\title{
GAMBARAN TINGKAT PENGETAHUAN IBU HAMIL TENTANG TANDA- TANDA BAHAYA KEHAMILAN TRIMESTER I DI PUSKESMAS KARANG PULE
}

\author{
Nurul Qomariah Rista Andaruni ${ }^{*}$, Catur Esty Pamungkas*, Cahaya Indah Lestari* \\ ${ }^{1 *}$ Kebidanan, Universitas Muhammadiyah Mataram, rista.gallouine@gmail.com
}

\begin{tabular}{l} 
INFO ARTIKEL \\
\hline Riwayat Artikel: \\
Diterima: 29-03-2017 \\
Disetujui: 01-07-2017 \\
\end{tabular}

\section{Kata Kunci:}

Tingkat Pengetahuan Tanda-Tanda Bahaya Kehamilan Trimester I

\begin{abstract}
ABSTRAK
Abstrak: Semakin tinggi pengetahuan ibu tentang tanda bahaya dalam kehamilan, maka semakin rendahnya kejadian bahaya pada ibu hamil. Tujuan untuk mengetahui gambaran tingkat pengetahuan ibu hamil tentang tanda-tanda bahaya kehamilan trimester I di Puskesmas Karang Pule. Penelitian ini menggunakan metode deskriptif dengan pendekatan cross sectional. Populasi dalam penelitian ini adalah semua ibu hamil trimester I yang datang berkunjung ke Puskesmas Karang Pule tahun 2016. Teknik pengambilan sampel yang digunakan adalah teknik non probability dengan metode accidental sampling sehingga sampel yang diambil sebesar 30 orang dengan pertimbangan batas minimal sampel yang ditetapkan. Pengumpulan data dilakukan dengan wawancara mengunakan alat bantu kuesioner. Analisis data dilakukan dengan menggunakan analisis univariat. Hasil penelitian menunjukan bahwa sebagian besar responden besar responden berusia 20-35 tahun sebanyak 23 orang (76,7\%), berpendidikan dasar sebanyak 19 orang (63,3\%), tidak bekerja sebanyak 20 orang $(66,7 \%)$, sedangkan dari segi tingkat pengetahuan responden diketahui sebagaian besar berpengetahuan cukup dan berumur 20-35 tahun, berpendidikan dasar dan tidak bekerja. Gambaran tingkat pengetahuan ibu hamil tentang tanda-tanda bahaya kehamilan trimester I di Puskesmas Karang Pule tahun menunjukkan sebagian besar responden berpengetahuan cukup dan berumur 20-35 tahun, berpendidikan dasar dan tidak bekerja.
\end{abstract}

\begin{abstract}
The higher level mother's knowledge about the danger signs in pregnancy, then the low occurrence of danger on pregnant women. Objective to know the description of the level of knowledge of pregnant women about the danger signs of pregnancy trimester I in Year 2016 Karang Pule health centers. This research uses descriptive method with cross sectional approach. The population in this research is all the I trimester of pregnant women who come to visit Clinics Karang Pule in 2016. The technique of sampling technique used was a non probability sampling methods with accidental so that samples taken by 30 people with consideration of minimum sample set. Data collection was done with interviews using questionnaire tool. Data analysis was conducted using univariate analysis. Results of the study showed that most respondents large respondents aged 20-35 years as many as 23 people (76.7\%), basic educated as much as 19 people (63.3\%), did not work as many as 20 people (66.7\%), while in terms of level of knowledge the respondent known to most knowledgeable enough and 20-35 years old, educated basis and does not work. The description of the level of knowledge of pregnant women about the danger signs of pregnancy trimester I at primary health care of Karang Pule showed the majority of respondents knowledgeable enough and 2035 years old, educated basis and does not work.
\end{abstract}




\section{A. LATAR BELAKANG}

Mengalami masa kehamilan, bagi sebagian wanita yang sudah menikah adalah puncak prestasi bagi wanita dalam kehidupan. Kehadiran anak di tengah perjalanan perkawinan merupakan dambaan bagi semua pasangan suami istri. Akan tetapi, tidak setiap ibu hamil dapat mengupayakan kehamilan untuk tumbuh dan berkembang. Oleh karena itu, sangat mudah untuk dipahami bahwa agar bayi lahir tetap sehat, persyaratan yang utama dengan menjaga dan merawat kesehatan ibu dan janin (Prasetyo, 2008).

Dalam banyak masyrakat defmisi medis dan legal kehamilan manusia dibagi menjadi tiga periode triwulan, sebagai cam memudahkan tahap berbeda dari perkembangan janin. Triwulan pertama membawa resiko tertinggi keguguran (kematian alami embrio atau janin), sedangkan pada masa triwulan ke-2 perkembangan janin dapat dimonitor dan didiagnosa. Triwulan ke3 menandakan awal 'viabilitas' yang berarti janin dapat tetap hidup bila terjadi kelahiran awal alami atau kelahiran dipaksakan (Cahyo, 2009). Ada beberapa hal yang harus diperhatikan untuk kesehatan kandungan ibu dan janinnya adalah tanda bahaya pada ibu hamil. Tanda bahaya kehamilan adalah tanda yang mengindikasikan adanya bahaya yang dapat terjadi selama kehamilan atau periode antenatal, yang apabila tidak dilaporkan atau tidak terdeteksi bisa menyebabkan kematian ibu (Pusdiknakes, 2005).

Faktor penyebab resiko kematian dan kesakitan ibu salah satunya adalah karena tidak terdeteksinya tanda bahaya se lama kehamilan karena kunjungan ANC yang tidak teratur. Banyak faktor yang melatar belakangi terjadinya hal tersebut, diantaranya faktor ketidakpatuhan ibu hamil dalam melaksanakn ANC secara teratur atau tidak sama sekali, selain itu ketidaktahuan ibu hamil dalam mengenal tanda bahaya kehamilan. Dapat diidentifikasi ada beberapa faktor yang dapat mempengaruhi tentang resiko tinggi tanda bahaya pada kehamilan, antara lain adalah pengetahuan. Sebagai salah satu faktor pengetahuan ibu hamil tentang tanda bahaya pada kehamilan sangat penting sekali peranannya dalam mendeteksi sejak dini. Sehingga dapat dikatakan semakin tinggi pengetahuan ibu tentang tanda bahaya dalam kehamilan maka, semakin rendahnya kejadian bahaya pada ibu hamil, sebaliknya bagi ibu yang memiliki pengetahuan yang rendah atau tidak mengetahui tentang tanda bahaya pada kehamilan maka, akan berisiko tinggi mengalami tanda bahaya pada kehamilan (Depkes, 2001).

Dari hasil studi pendahuluan yang dilakukan pada ibu hamil trimester I bahwa sebanyak 10 orang (60\%) yang masih kurang pengetahuannya tentang tandatanda bahaya kehamilan. Berdasarkan Tatar belakang tersebut, peneliti tertarik mengadakan penelitian mengenai gambaran tingkat pengetahuan ibu hamil tentang tandatanda bahaya kehamilan trimester I di Puskesmas Karang Pule.

\section{B. METODE PENELITIAN}

Penelitian ini dilaksanakan di Puskesmas Karang Pule Kota Mataram yang dilaksanakan pada tahun 2016. Penelitian ini menggunakan metode deskriptif dengan pendekatan cross sectional. Populasi dalam penelitian ini adalah semua ibu hamil trimester I yang datang berkunjung ke Puskesmas Karang Pule.

Penelitian ini menggunakan metode deskriptif dengan pendekatan cross sectional. Teknik pengambilan sampel yang digunakan adalah teknik non probability dengan metode accidental sampling, sehingga sampel yang diambil sebesar 30 orang dengan pertimbangan batas minimal sampel yang ditetapkan. Pengumpulan data dilakukan dengan wawancara mengunakan alat bantu kuesioner.

Pada penelitian ini menggunakan analisa univariat dimana hanya mendiskripsikan tiap-tiap variabel yaitu karakteristik (umur, pendidikan, dan pekerjaan) dan pengetahuan ibu hamil tentang tanda-tanda bahaya kehamilan.

\section{HASIL DAN PEMBAHASAN}

\section{Karakteristik Responden a. Berdasarkan Umur}

Karakteristik responden berdasarkan umur di wilayah kerja Puskesmas Karang Pule pada tahun 2014 dimana sebagian kecil jumlah responden umur $>20$ tahun sebanyak 3 orang dengan frekuensinya (10\%), dan sebagian besar responden umur 20-35 tahun sebanyak 23 orang $(76,7 \%)$.

Masa kehamilan reproduksi wanita pada dasarnya dapat dibagi dalam tiga periode, yakni kurun reproduksi muda (15-19 tahun) atau ( $<20$ tahun), kurun reproduksi sehat ( 20-35 tahun), dan kurun waktu reproduksi tua (36-45 tahun) atau >35 tahun. Pembagian ini didasarkan atas data epidemiologi bahwa resiko kehamilan dan persalinan baik bagi ibu maupun bagi anak lebih tinggi pada usia kurang dari 20 tahun, paling rendah pada usia 20-35 tahun dan meningkat lagi secara tajam lebih dari 35 tahun (Siswosudarmo, 2001). Usia 20-35 tahun merupakan usia yang sudah matang dan cukup memiliki pengetahuan dan pengalaman baik dari segi kematangan dalam berfikir maupun mental untuk menjalani rumah tangga (Hanifa, 2002).

\section{b. Berdasarkan Pendidikan}

Karakteristik responden berdasarkan pendidikan dapat diketahui sebagian besar responden berpendidikan dasar yaitu sebanyak 19 orang atau $(63,3 \%)$ dan sebagian kecil responden berpendidikan tinggi yaitu sebanyak 3 orang atau (10\%). Berdasarkan tabulasi silang antara pegetahuan dengan pendidikan ternyata yang memiliki pengetahuan baik lebih banyak dari pendidikan dasar dan menengah, hal ini sejalan dengan yang di ungkapkan oleh Notoatmodjo (2005) 
menyatakan bahwa semakin tinggi tingkat pendidikan seseorang maka makin mudah menerima informasi sehingga makin banyak pengetahuan yang dimiliki, sebaliknya pendidikan yang kurang akan menghambat perkembangan seseorang terhadap nilai-nilai yang baru diperkenalkan.

Pendidikan dapat mempengaruhi sesorang termasuk juga prilaku sheering akan pola hidup, terutama dalam motivasi untuk sikap berperan serta dalam pembangunan kesehatan. Makin tinggi tingkat pendidikan sesorang, makin mudah menerima informasi sehingga makin banyak pula pengetahuan yang dimiliki. Sebaliknya pendidikan yang kurang akan menghambat perkembangan sikap sesorang akan nilai-nilai yang baru diperkenalkan (Notoatmodjo, 2007).

Sehingga dapat dikatakan pendidikan mempunyai pengaruh positif terhadap tingkat tindakan ibu ketika mengalami tanda bahaya kehamilan. Berkaitan dengan informasi yang mereka terima, wanita yang berpendidikan dan lebih siap siaga bila terjadi hal-hal yang membahayakan kehamilan.

\section{c. Berdasarkan pekerjaan}

Karakteristik responden berdasarkan pekerjaan di wilayah kerja puskesmas karang pule diketahui bahwa sebagian besar responden tidak bekerja sebanyak 20 orang atau (66,7\%), dan sebagian kecil yang bekerja sebanyak 10 orang atau (33,3\%). Hal ini senada dengan pendapat yang di ungkapkan oleh Nursalam bahwa pekerjaan sesorang akan dapat menunjukkan tingkat sosial ekonomi yang dapat mempengaruhi kemampuan dalam menyerap informasi. Bekerja bagi ibu-ibu akan mempunyai pengaruh terhadap kehidupan keluarga. Ibu yang bekerja biasanya memperoleh informasi lebih banyak daripada ibu yang tidak bekerja (Nursalam, 2008).

Jenis pekerjaan ibu juga dapat memberikan informasi dan wawasan yang berbeda bagi ibu tentang hal-hal yang baru masuk dalam hal informasi kesehatan, karena ibu akan berintraksi dengan orang lain sehingga dapat menambah pengalaman dan pengetahuan tentang informasi baru (Widyatun, 2009).

\section{Gambaran pengetahuan \\ a. Tingkat pengetahuan}

Data pengetahuan ibu hamil tentang tanda-tanda bahaya kehamilan trimester I di puskesmas karang pule diperoleh, data sebagian besar responden memiliki pengetahuan cukup yaitu 18 orang atau (60\%), dan sebagian kecil responden memiliki pengetahuan yang kurang yaitu 4 orang atau (13,3\%). Hal ini sesuai dengan hasil penelitian Nuraini (2011), dari segi pengetahuan, diperoleh data bahwa tingkat pengetahuan baik yaitu sebanyak 19 orang (42.2\%), dan data pengetahuan tidak baik yaitu sebanyak 1 orang (2.2\%). Pengetahuan merupakan hasil penginderaan manusia. Sebagian besar pengetahuan sesorang diperoleh melalui indera pendengaran (telinga) dan indera penglihatan (mats) (saryono, 2005).

\section{b. Gambaran tingkat pengetahuan dan umur di Puskesmas Karang Pule}

Sebagian besar responden yang mempunyai pengetahuan cukup terdapat pad ibu yang berumur 2035 tahun sebanyak 12 orang atau (40,0\%) dan sebagian kecil responden yang mempunyai pengetahuan kurang terdapat pada ibu berumur $<20$ tahun sebanyak 1 orang atau (33,3\%). Karena dengan bertambahnya usia seseorang sangat besar pengaruh terhadap pengetahuan (Notoatnodjo, 2005)

\section{c. Gambaran tingkat pengetahuan dan pendidikan di Puskesmas Karang Pule}

Sebagian besar responden mempunyai pengetahuan cukup yang terdapat pada pendidikan dasar sebanyak 10 orang atau (33,3\%), dan sebagian kecil responden mempunyai pengetahuan baik terdapat pada pendidikan tinggi sebanyak 1 orang atau (3,3\%). Hal ini sejalan dengan pendapat bahwa tingkat pengetahuan seseorang yang berpendidikan tinggi pengetahuan akan berbeda dengan orang yang berpendidikan rendah (Notoatmodjo, 2005).

\section{d. Gambaran tingkat pengetahuan dan pekerjaan di Puskesmas Karang Pule.}

Data tentang pengetahuan dan pekerjaan diperoleh data sebagian besar responden yang tergolong memiliki pengetahuan cukup terdapat pada responden yang tidak bekerja sebanyak 11 orang $(36,7)$, dan sebagian kecil responden yang memiliki pengetahuan baik terdapat pada responden yang bekerja sebanyak 3 orang (10,0\%). Hal ini menunjukkan bahwa pekerjaan dapat mempengaruhi pengetahuan sesorang, dan ini sesuai dengan pendapatnya Notoatmodjo (2005) bahwa sesorang yang bekerja pengetahuannya akan lebih lugs dari pada seseorang yang tidak bekerja, karena dengan bekerja sesorang akan mempunyai banyak informasi.

\section{SIMPULAN DAN SARAN}

Hasil penelitian dan pembahasan dalam penelitian dapat disimpulkan bahwa berdasarkan gambaran tingkat pengetahuan ibu hamil tentang tanda-tanda bahaya kehamilan trimester I di puskesmas karang pule tahun 2014 menunjukkan sebagian besar pengetahuan cukup, dimana responden yang berpengetahuan cukup, berumur 20-35 tahun, berpendidikan dasar dan tidak bekerja.

Saran dari penelitian ini agar lebih meningkatkan pelayanan secara profesional dengan memberikan penyuluhan secara intensif, KIE, leaflet atau brosur tentang tanda-tanda bahaya kehamilan trimester I. 


\section{DAFTAR RUJUKAN}

[1] Cahyo, Atikah P. (2010). Berat Badan Lahir Rendah (BBLR). Yogyakarta : Nuha Medika.

[2] Depkes RI. (1999). Pedoman Pelayanan Kebidanan Dasar. Jakarta : Depkes RI.

[3] Hannifa, W. (2007). Ilmu Kebidanan. Jakarta : Yayasan Bina Pustaka.

[4] Notoatmodjo, S. (2010). Metode Penelitian Kesehatan. Jakarta : Rineka Cipta

[5] Pusdiknakes. (2003). Asuhan Kebidanan Post Partum. Jakarta: Pusdiknakes

[6] Prasetyono, DS. (2008). Buku Pintar ASI Eksklusif. Diva Press; Yogyakarta 